\title{
ZIRCONIA VERSUS COBALT CHROMIUM MESHWORK REINFORCEMENT OF IMPLANT-ASSISTED MANDIBULAR OVERDENTURE
}

\author{
Mohamed Ahmed Alkhodary*
}

\begin{abstract}
Introduction : This work aimed at testing the mechanical behavior of non-metallic enforcement of an implant-assisted mandibular overdenture denture base with a zirconium meshwork and compared its behavior to that of cobalt chromium meshwork under fatigue cyclic loading and fracture resistance.
\end{abstract}

Materials and Methods: Thirty completely edentulous models in which 2 laboratory implant analogues were secured in the position of the teeth 33 and 43 with ball abutments were used, 10 overdentures of group I had cobalt-chromium meshwork reinforcement of $1 \mathrm{~mm}$ thickness, group II had 10 overdentures reinforced with $0.5 \mathrm{~mm}$ zirconia framework, and group III had 10 dentures with $1 \mathrm{~mm}$ zirconia reinforcing framework, the 3 groups were subjected to fatigue cyclic loading and fracture testing.

Results: Group I did not show complete fracture, only cracks in the denture base. group II showed complete fracture of its samples, and only 6 samples of group III showed complete fracture with cracks in the remaining 4 . There were significant differences between groups I and II, groups I and III, and groups II and III where the fracture load was significantly greatest for group I, followed by group III, and finally group II.

Conclusion: The Co-Cr meshworks provided the strongest reinforcement of the overdenture bases as compared to zirconia frameworks. The $1 \mathrm{~mm}$ thickness zirconia meshwork was more resistant to fracture than the $0.5 \mathrm{~mm}$ zirconia framework, but weaker than the Co-Cr framework, however, its recorded resistance to fatigue cyclic loading and fracture was thought to provide an acceptable clinical service lifetime.

KEY WORDS: Denture base fracture, cobalt-chromium meshwork reinforcement, zirconia

\footnotetext{
* Associate Professor, Department of Prosthodontics, Faculty of Dentistry, Alexandria University, EGYPT.
} 


\section{INTRODUCTION}

Whether implant-supported mandibular overdentures were made of conventionally heat cured or CAD/CAM milled acrylic resin, fracture of the denture bases was encountered, specifically near the abutment housings. ${ }^{1}$ A claim has been made that at least $2 \mathrm{~mm}$ thickness of acrylic resin should exist at these fracture sites to provide resistance against fracture, ${ }^{2}$ however, the use of a metal framework to reinforce the denture bases was found more efficient in two-implant assisted overdentures to counteract the effect of the cantilever distal to the abutments. ${ }^{3-5}$

Zirconia was recently suggested to replace metals in dental prostheses, and improve the mechanical properties of complete denture bases, ${ }^{6,7}$ where its addition in nano particles form improved the transverse strength of the heat polymerized denture bases, ${ }^{8,9}$ however, still the addition of cobalt chromium meshes or stainless-steel wires produced better fracture resistance. ${ }^{10}$

The combination of nano-zirconia, titanium dioxide and other several organic and inorganic fillers was shown to increase the impact and flexural strength as compared to non-reinforced acrylic resins. ${ }^{11-17}$ Such improvements in material science offered better strength and esthetics of denture base materials, ${ }^{18,19}$ however, there was a possibility of particle agglomeration as the nano-particle concentrations increased; this paved the way for the use of unidirectional E-glass fibers which were found to provide better mechanical properties to denture bases than zirconium and titanium oxide particles, ${ }^{20,21}$ but was still inferior to cobalt chromium mesh reinforced denture bases. ${ }^{22}$

Several other improvements of the denture base mechanical properties exist, such as the use of Metrocryl HI high-impact resins that, when combined with zirconia particles, increased the transverse strength by $76 \%,{ }^{23}$ or the addition of elastomers that improved the acrylic resin impact strength with minimal effect on Youngs modulus. ${ }^{25-30}$
However, in spite of all such improvements, complete denture bases suffered localized fractures and cracking under fatigue cyclic loading whether with zirconia impregnated polymethyl methacrylate (PMMA), ${ }^{31}$ or when made out of high-impact (HI) heat-polymerized PMMA resin. ${ }^{32}$

Based on the previously presented data, it seemed that the mechanical enforcement of the denture base with metal substructure provided the best results, ${ }^{33-37}$ However,further studies were still needed to study the behavior of metal free reinforcements of the denture base, ${ }^{38,39}$ specifically under cyclic loading. ${ }^{40-43}$ This work aimed at testing the mechanical behavior of non-metallic enforcement of an implant-assisted mandibular overdenture denture base with a zirconium meshwork and compared its behavior to that of cobalt chromium meshwork under fatigue cyclic loading and fracture resistance.

\section{MATERIALS AND METHODS}

Thirty identical study models were used in this work, which were duplicates of a completely edentulous patient master model, in which 2 laboratory implant analogues were secured in the position of the teeth 33 and 43, the models were poured in type III extra hard dental stones (Model Hard Stone, ENRST HIRNICHS Dental GmbH, Germany). Tow ball abutments (Zimmer, Inc, TSV, Carlsbad, Calif, USA) were secured to the implant analogues with their metal housings seated in place as seen in figure 1 .

For group I, relief wax was adapted to 10 of the study models, and tissue stops spaces were created in the posterior areas of the edentulous arches. These modified study models were duplicated to provide the refractory casts on which the cobalt chromium (TALLADIUM Vi-Tal, Batch \# 060413, Talladium, Inc. CA, USA) meshwork wax patterns were fabricated, sprued, invested, cast, and finished. The metal meshworks were then seated on the study models to ensure passive fit over the metal hosing of 
the implants ball abutments, and were bonded to the metal housings with acrylic resin. The mandibular complete overdentures were fabricated to the wax stage, and flasked on duplicates of the study model to which the metal meshworks were secured to produce 10 overdentures of group I as seen in figure 2.

For group II, 10 study models were modified as for group I with relief wax, with the metal housings of the implants ball abutments secured in place, then these models were scanned using the bench top scanner (Kavo ARCTICA AutoScan) to produce a virtual model on which the zirconium meshworks were designed to be $0.5 \mathrm{~mm}$ in thickness, milled using Cercon disk, (Dentsply, Sirona, Germany) seen in figure 3, with the Sirona CAD/CAM, and sintered. For group III, ten zirconium meshworks were produced exactly as for group II, however, their thickness was set to be $1 \mathrm{~mm}$. The zirconia meshworks of groups II and III were then seated on the study models to ensure passive fit over the metal housings of the abutments, and similar to the procedures in group I, 10 overdentures were produced as seen in figure 4 . The acrylic resin used in making the overdentures in the three groups of this study was the conventionally heat cured acrylic

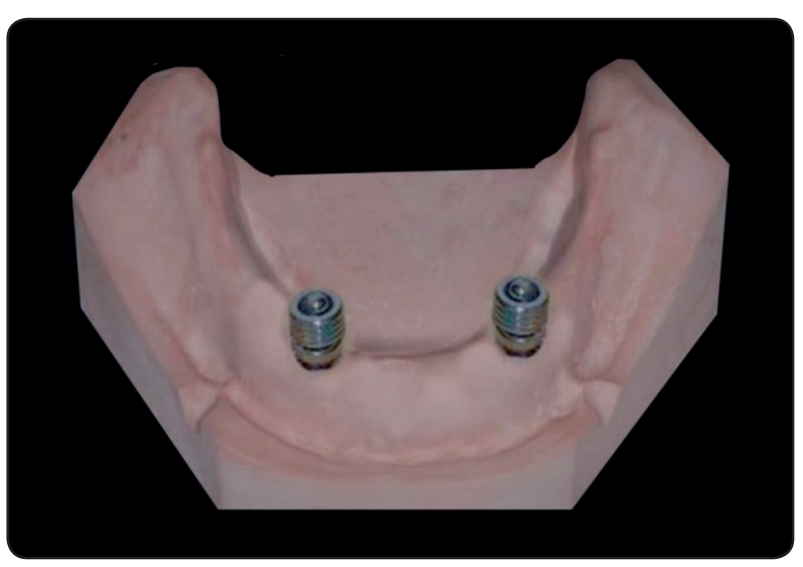

Fig. (1): The study model with the ball abutments and metal housings. resin (Vertex SR, Vertex Dental, Zeist, Netherland) with conventional compression molding using slow heat curing cycle at $74 \mathrm{C}$ for 9 hours.

The overdentures in each group were subjected to cyclic fatigue loading using a T-shaped bar applied to the second molar area while the dentures were fixed in place anteriorly at three points namely: the midline, and at each metal housing of the abutments, on an acrylic duplicate of the study model that was relieved starting from the area distal to the ball abutments and covered with a soft silicone layer to mimic the cushioning effect of the mucosa overlying the edentulous ridge. The fatigue loading was conducted using a chewing simulator (CS-4.8, SD Mechatronik, Feldkirchen-Westerham, Germany) at $80 \mathrm{~N}$ at $1 \mathrm{~Hz}$ for 300,000 cycles. Then, as seen in figure 5, the soft silicone was removed from the acrylic cast and fracture loading of each group was conducted using a universal testing machine (Lloyd LRX, Lloyd Instruments) applying a stainless-steel ball $1 \mathrm{~cm}$ in diameter to the free end of each denture bilaterally at a cross head speed of $1 \mathrm{~mm} / \mathrm{min}$ until fracture occurred. Finally, the statistical analysis of the fracture values was statistically analyzed using the one-way ANOVA (SPSS version 20 for windows) at a significance level of $\mathrm{p}<.05$.

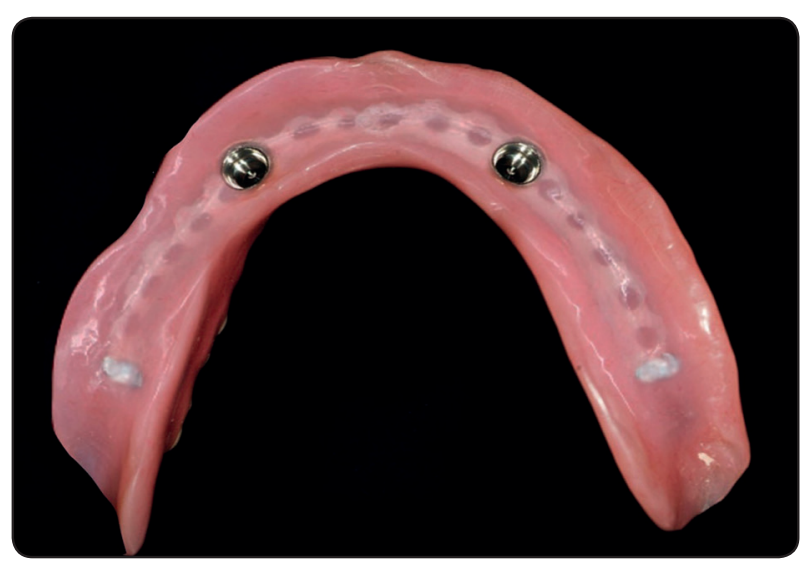

Fig. (2): Group I chrome-cobalt reinforced overdenture 


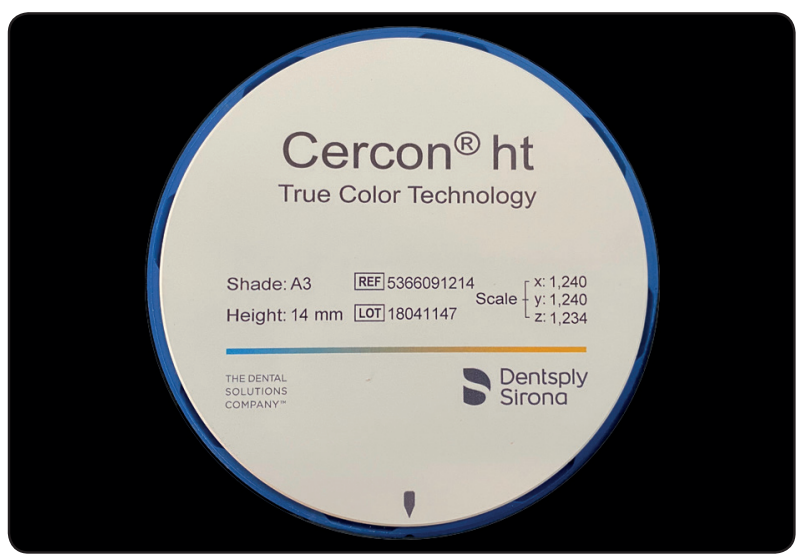

Fig. (3): The zirconium CAD/CAM disk.

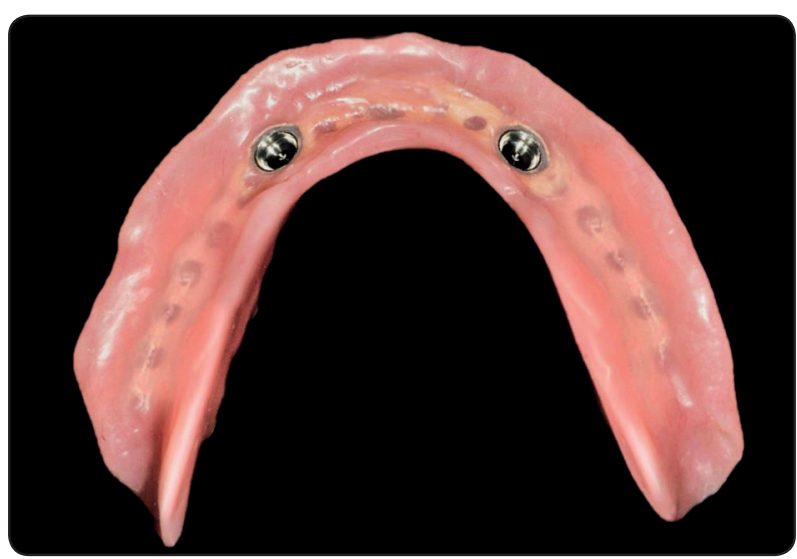

Fig. (4): Group II zirconium reinforced overdenture

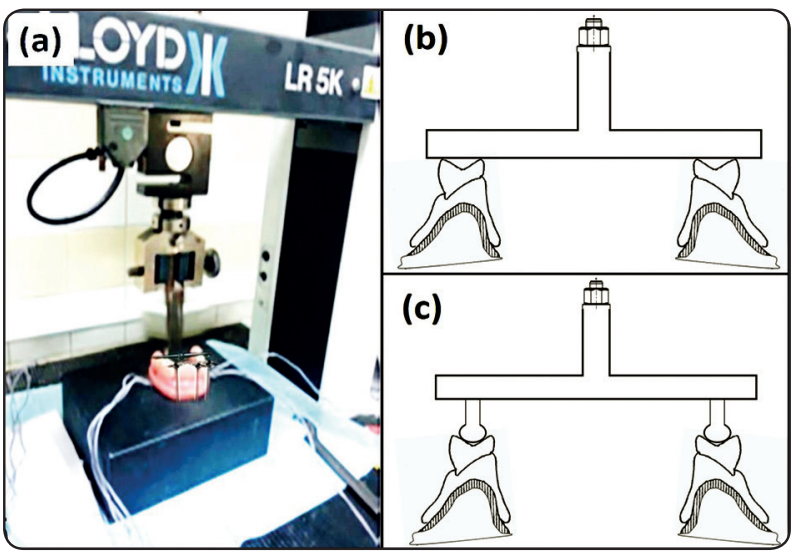

Fig. (5): The mechanical testing: (a) the universal testing machine, (b) schematic illustration of the T-bar used for cyclic fatigue testing, (c) schematic illustration of the stainless-steel ball used for fracture testing.

\section{RESULTS}

Considering the fracture modes, the samples of group I did not show complete fracture, their failure was in the form of cracks in the denture base starting from the location of the metal housing of the ball abutments to the location of the loading stainless steels balls with only bending of the Co$\mathrm{Cr}$ meshwork located within the denture bases, the samples of group II showed complete fracture in its 10 samples immediately distal to the housing of the ball abutments with the zirconia meshworks fractured at such locations, on the other hand, only 6 samples of group III showed complete fracture at locations distal to the fracture locations reported in group II. Comparison of the fracture strength between groups revealed a significant difference between groups I and II, groups I and III, and groups II and III where the fracture load was significantly greatest for group I, followed by group III, and finally group II as seen in figure 6 and tables 1 and 2 .

TABLE (1): Fracture strength (N) for each group

\begin{tabular}{cc}
\hline Group & Fracture strength (N) \\
\hline Group I & $4756.4 \pm 564$ \\
Group II & $2078.3 \pm 289.6$ \\
Group III & $3296 \pm 320.2$ \\
\hline
\end{tabular}

TABLE (2): Comparison of fracture strength between groups

\begin{tabular}{ll}
\hline Group I versus group II & $P=0.01$ \\
\hline Group I versus group III & $P=0.02$ \\
\hline Group II versus group III & $P=0.04$
\end{tabular}




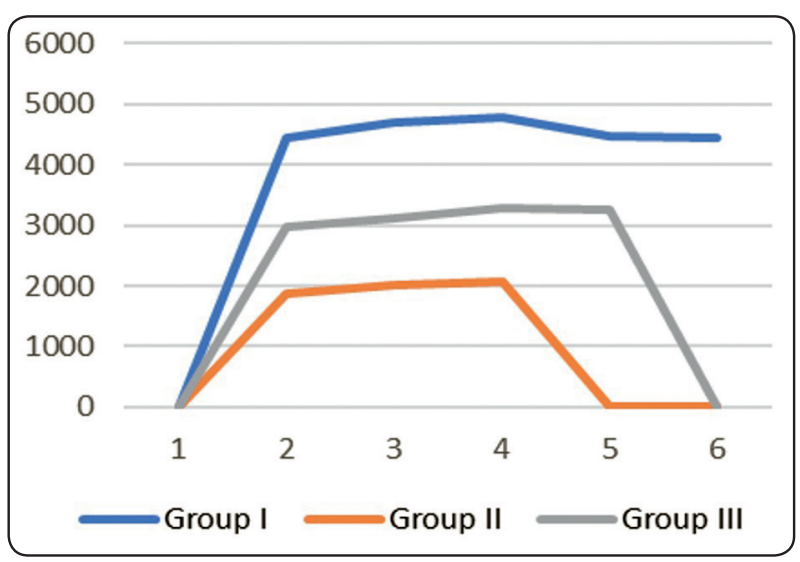

Fig. (6): Fracture loading (N/min) of the studied reinforced denture bases.

\section{DISCUSSION}

According to Radi and Abdel-Hamid ${ }^{29}$ heat cured acrylic resin provided denture base material that can easily be repaired and relined as compared to other available metal or ceramic materials, Aguirre et $\mathrm{al}^{27}$ further added that when these bases were made out of CAD/CAM milled pre-polymerized disks; their resistance to fatigue was increased, however, when acrylic resin overdentures were considered, Aly ${ }^{1}$ found that there was no significant difference between conventionally cured and CAD/CAM dentures specially near the abutment housings locations. Increasing the denture base resistance to fracture was advocated by Tokgoz et $\mathrm{al}^{2}$ who suggested increasing the denture thickness to a minimum of $2 \mathrm{~mm}$, or by Zidan et $\mathrm{al}^{31}$ and Rodrigues $^{32}$ who used zirconia nanoparticles, however, these bases still suffered cracking and fractures. On the other hand, the work of Alrashed ${ }^{3}$ suggested a maneuver similar to that used in the current work in which a metal framework was used to reinforce the denture base, and make it resistant to the stresses of the cantilever distal to the abutments of the 2 implant assisted overdentures as proved by Farrag et al, ${ }^{4}$ and El-Zawahry et $\mathrm{l}^{5}$ who favored the use of 2 implants in the canine region to support mandibular overdentures.
The current study suggested the use of zirconia meshwork to reinforce the acrylic denture base, this hypothesis was in agreement with Takano and Sakurai ${ }^{7}$ who stated that zirconia had advantageous properties to be used in denture bases, and Kumar et $\mathrm{al}^{6}$ who claimed that CAD/CAM manufacturing of zirconia reduced its cyclic fatigue failure, however, and in agreement with the results of this study, Bashi and Al-Nema ${ }^{9}$ found that the Co-Cr meshworks provided the best reinforcement of denture bases when compared to any other material as also proven by the work of $\operatorname{Resin}^{10}$ on the metal reinforcement of denture bases.

The experimental design of this study was also in agreement with Özçelik et al ${ }^{33}$ who tackled the same problem, and $\mathrm{Im}$ et $\mathrm{al}^{22}$ who used a similar fatigue cyclic loading of 300,000 cycles, and fracture testing, and concluded similar result to that of this study where Co-Cr meshwork reinforcement was significantly better than other forms of reinforcement. Also, similar to the framework design in this study, Poštić ${ }^{34}$ suggested the incorporation of the abutment metal housings in the reinforcement framework to prevent fracture of the denture bases in such areas.

The meshwork reinforcement of the denture bases used in this study did not exceed $1 \mathrm{~mm}$ in thickness in order not to increase the overall thickness of the denture base that might encroach upon the inter arch space, and though it might seem more suitable for resorbed ridges, Grageda and Rieck $^{35}$ recommended such reinforcement even with well-developed edentulous ridges. Cruz et al $^{36}$ also suggested the same reinforcement, however, in contrast to this study, they recommended a single implant overdenture with locator attachment.

The results of this study showed that the $1 \mathrm{~mm}$ thick Co-Cr meshworks were able to resist fatigue cyclic loading and fracture as compared to the 0.5and 1-mm thick zirconia frameworks, this finding came in agreement with Zhang et $\mathrm{al}^{40}$ who studied the fatigue behavior of zirconia and showed that zirconia exhibited more fracture after cyclic loading leading to the recommendation to its use in the 
anterior rather than the posterior areas of the dental arch, however, it is worth mentioning that Zhang et $\mathrm{al}^{40}$ used 5 million fatigue cycles similar to 20 years of clinical service. However, in a similar study on the fatigue of zirconia under cyclic loading, Studart et $\mathrm{al}^{41}$ found that crack propagation in zirconia frameworks was significantly subcritical, and once the initial mechanical properties of the zirconia frameworks were sufficiently high, then their lifetime was good enough for a minimum of 20 years in clinical service.

In conclusion, and considering the digital transformation of the production of complete dentures, this study recommended the use of the $1 \mathrm{~mm}$ thick zirconia frame work to reinforce the implant overdenture bases, and although it is possible to manufacture $\mathrm{Co}-\mathrm{Cr}$ frameworks digitally as advocated by Piao et al, ${ }^{37}$ the zirconia meshworks can similarly be digitally fabricated as conducted in the current study, and as advocated by $\mathrm{Cho}^{38}$ to provide a metal free reinforcement, that might not be as strong, but of strength close to the metal reinforcement, with potentially long lifetime in clinical service.

Finally, considering the limitations if this study, it was noticed that this study used conventional, nonreinforced acrylic resin, cured with conventional method, and metal frameworks of only one design, and tested only two thicknesses of the zirconia meshworks.

\section{CONCLUSIONS}

Taking the limitations of this study in consideration, the followings were concluded:

1- The Co-Cr meshworks provided the strongest reinforcement of the implant assisted overdenture bases as compared to zirconia frameworks.

2- The $1 \mathrm{~mm}$ thickness zirconia meshwork was more resistant to fracture than the $0.5 \mathrm{~mm}$ zirconia framework, but weaker than the $\mathrm{Co}-\mathrm{Cr}$ framework, however, its recorded resistance to fatigue cyclic loading and fracture was thought to provide an acceptable clinical service lifetime.

\section{RECOMMENDATIONS}

1- Further clinical investigation of the studied zirconia frameworks is required.

2- Further research is required to examine the potential of incorporating the $\mathrm{CAD} / \mathrm{CAM}$ production of the zirconia frameworks into the full digital workflow of complete dentures.

\section{REFERENCES}

1. Aly M. Fracture incidence in implant-retained mandibular overdenture constructed by either conventional method or CAD/CAM technology-A one year follow up. Egyptian Dental Journal. 2021 Apr 1;67(2):1417-22.

2. Tokgoz S, Ozdiler A, Gencel B, Bozdag E, Isık-Ozkol G. Effects of denture base thicknesses and reinforcement on fracture strength in mandibular implant overdenture with bar attachment: under various acrylic resin types. European journal of dentistry. 2019 Feb;13(01):064-8.

3. Alrashed MH. The influence of single and double implants on the strain distribution of mandibular metal-reinforced overdentures (Doctoral dissertation, University of Otago, 2014).

4. Farrag M, Rostom D, Hamed H. Stress distribtuion analysis for the mandibular screw-retained full arch acrylic prosthesis with different cantilever extension ( $3 \mathrm{~d}$ finite element analysis). Egyptian dental journal. 2021 apr 1;67(2):1517-25.

5. El-Zawahry MM, Ibraheem EM, Nassani MZ, Ghorab SA, El-Anwar MI. Stress analysis of mandibular implant overdentures retained with one, two, or four ball attachments: A finite element study. Dental research journal. 2018 Nov;15(6):437.

6. Kumar CG, Shruthi DP, Raj KS, Kalpana D, Harish G. Zirconia: Substitute for metal ceramics. Journal of Orofacial Research. 2014:209-12.

7. Takano T, Sakurai K. Overview of zirconia: Application as denture base material substituting for metal. International Journal of Prosthodontics \& Restorative Dentistry. 2013 Oct 1;3(4):153.

8. Vojdani, M., and A. A. R. Khaledi. "Transverse strength of reinforced denture base resin with metal wire and E-glass fibers." (2006): 167-172.

9. Bashi TK, Al-Nema LM. Evaluation of some mechanical properties of reinforced acrylic resin denture base material 
(an in vitro study). Al-Rafidain dental journal. 2009 Jun $1 ; 9(1): 57-65$.

10. Resin MR. Effect of 4-META on Transverse Strength of Metal-Reinforced Denture Base Acrylic Resin. J Dent Assoc Thai. 2012 Jan;62(1).

11. Asopa V, Suresh S, Khandelwal M, Sharma V, Asopa SS, Kaira LS. A comparative evaluation of properties of zirconia reinforced high impact acrylic resin with that of high impact acrylic resin. The Saudi Journal for Dental Research. 2015 Jul 1;6(2):146-51.

12. Alhareb AO, Akil HM, Ahmad ZA. Mechanical properties of PMMA denture base reinforced by nitrile rubber particles with A12O3/YSZ fillers. Procedia Manufacturing. 2015 Jan 1;2:301-6.

13. Gad M, ArRejaie AS, Abdel-Halim MS, Rahoma A. The reinforcement effect of nano-zirconia on the transverse strength of repaired acrylic denture base. International journal of dentistry. 2016 Jun 2;2016.

14. Abdel-Karim UM, El-Safty SM, Kenawy ER. Surface roughneSS, hardneSS, color Stability, Water Sorption and Water Solubility of pMMa denture baSeMaterial reinforced With SyntheSizedinorganic, organic, and hybrid nanofiberS. Egyptian Dental Journal. 2018 Oct 1;64(4-October (Fixed Prosthodontics, Dental Materials, Conservative Dentistry \& Endodontics)):3593-608.

15. Somani MV, Khandelwal M, Punia V, Sharma V. The effect of incorporating various reinforcement materials on flexural strength and impact strength of polymethylmethacrylate: A meta-analysis. The Journal of the Indian Prosthodontic Society. 2019 Apr;19(2):101.

16. Gad MM, Al-Thobity AM, Rahoma A, Abualsaud R, AlHarbi FA, Akhtar S. Reinforcement of PMMA denture base material with a mixture of $\mathrm{ZrO} 2$ nanoparticles and glass fibers. International journal of dentistry. 2019 Jan 28;2019.

17. Kumar A, Kumar R, Vamshikiran K, Deepthi G, Kumar N, Akhilesh M. Evaluation of Impact Strength of Dental Acrylic Resins by Incorporation of TiO2 Nanoparticles Using Two Different Processing Techniques. The journal of contemporary dental practice. 2019 Oct 1;20(10):1184-9.

18. Emera RM, Altonbary GY, Elbashir SA. Comparison between all zirconia, all PEEK, and zirconia-PEEK telescopic attachments for two implants retained mandibular complete overdentures: in vitro stress analysis study. Journal of Dental Implants. 2019 Jan 1;9(1):24.
19. Prajwala N, Kumar CR, Sujesh M, Rao DC, Pavani L. Denture base reinforcing materials-A review. IP Annals of Prosthodontics and Restorative Dentistry. 2020 Jun 15;6(2):52-9.

20. Alhotan A, Yates J, Zidan S, Haider J, Silikas N. Assessing Fracture Toughness and Impact Strength of PMMA Reinforced with Nano-Particles and Fibre as Advanced Denture Base Materials. Materials. 2021 Jan;14(15):4127.

21. Alhotan A, Yates J, Zidan S, Haider J, Silikas N. Flexural Strength and Hardness of Filler-Reinforced PMMA Targeted for Denture Base Application. Materials. 2021 Jan;14(10):2659.

22. Im SM, Huh YH, Cho LR, Park CJ. Comparison of the fracture resistances of glass fiber mesh-and metal meshreinforced maxillary complete denture under dynamic fatigue loading. The journal of advanced prosthodontics. 2017 Feb 1;9(1):22-30.

23. Ayad NM, Badawi MF, Fatah AA. Effect of reinforcement of high-impact acrylic resin with zirconia on some physical and mechanical properties. Archives of Oral Research. 2008 Nov 29;4(3).

24. Pires-de-Souza FD, Panzeri H, Vieira MA, Garcia LD, Consani S. Impact and fracture resistance of an experimental acrylic polymer with elastomer in different proportions. Materials Research. 2009;12(4):415-8.

25. Faot F, Panza LH, Garcia RC, Cury AA. Impact and flexural strength, and fracture morphology of acrylic resins with impact modifiers. The open dentistry journal. 2009;3:137.

26. Asar NV, Albayrak H, Korkmaz T, Turkyilmaz I. Influence of various metal oxides on mechanical and physical properties of heat-cured polymethyl methacrylate denture base resins. The journal of advanced prosthodontics. 2013 Aug 1;5(3):241-7.

27. Aguirre BC, Chen JH, Kontogiorgos ED, Murchison DF, Nagy WW. Flexural strength of denture base acrylic resins processed by conventional and CAD-CAM methods. The Journal of prosthetic dentistry. 2020 Apr 1;123(4):641-6.

28. Maletin A, Bastajić J, Ristić I, Šarčev BP, Nešković I, Veljović T, Marković D. Testing of the fracture resistance of the heat-curing denture base acrylic resin.

29. Radi IA, Abdel-Hamid Dm. Fracture resistance of relined microwave-cured high impact versus conventional heatcured acrylic resin mandibular denture bases: an in vitro study. Egyptian dental journal. 2018 apr 1;64(2-april (fixed prosthodontics, dental materials, conservative dentistry \& endodontics)):1883-92. 
30. Chandrahari N, Kumar CR, SA R, Singh M, Singh S. Comparison of Fracture Resistance of Heat Cure Resins Polymerized by Conventional and Microwave Methods after Immersion in Artificial Saliva. The journal of contemporary dental practice. 2019 Jan 1;20(1):71-7.

31. Zidan S, Silikas N, Haider J, Alhotan A, Jahantigh J, Yates J. Evaluation of equivalent flexural strength for complete removable dentures made of zirconia-impregnated PMMA nanocomposites. Materials. 2020 Jan;13(11):2580.

32. Rodrigues AH. Metal reinforcement for implant-supported mandibular overdentures. The Journal of prosthetic dentistry. 2000 May 1;83(5):511-3.

33. Özçelik TB, Yılmaz B, Akçimen Y. Metal reinforcement for implant-supported mandibular overdentures. Journal of prosthetic dentistry. 2013 May 1;109(5):338-40.

34. Poštić SD. Design of complete denture reinforced with metal base. Stomatoloski glasnik Srbije. 2013;60(1):15-23.

35. Grageda E, Rieck B. Metal-reinforced single implant mandibular overdenture retained by an attachment: A clinical report. The Journal of prosthetic dentistry. 2014 Jan 1;111(1):16-9.

36. Cruz RS, Batista V, Lemos C. Esthetic metal reinforcement for fabrication of a complete maxillary denture. JSM Dent. 2017; 5:1096.
37. Piao XY, Shim JS, Park JM. Fabrication of MetalReinforced Complete Dentures Using the CAD-CAM Technique. Applied Sciences. 2021 Jan;11(16):7369.

38. Cho Y, Raigrodski AJ. The rehabilitation of an edentulous mandible with a CAD/CAM zirconia framework and heat-pressed lithium disilicate ceramic crowns: a clinical report. The Journal of prosthetic dentistry. 2014 Jun 1; 111(6):443-7.

39. Siewert B. Metal-free implant-supported restorations in the edentulous jaw. EDI J. 2018;3:68-74.

40. Zhang Y, Han JM, Zheng G, Lin H, Bai W, Zhao J, Shen Z. Fatigue behaviours of the zirconia dental restorations prepared by two manufacturing methods. Advances in Applied Ceramics. 2017 Oct 3;116(7):368-75.

41. Studart AR, Filser F, Kocher P, Gauckler LJ. Fatigue of zirconia under cyclic loading in water and its implications for the design of dental bridges. Dental materials. 2007 Jan 1;23(1):106-14.

42. Mahmood DJ, Braian M, Khan AS, Shabaz A, Larsson C. Fracture load of colored and non-colored high translucent zirconia three-unit fixed dental prosthesis frameworks. Acta biomaterialia odontologica Scandinavica. 2018 Jan $1 ; 4(1): 38-43$. 